\title{
Mental Health In Elite Athletes: Increased Awareness Requires An Early Intervention Framework to Respond to Athlete Needs
}

\author{
Rosemary Purcell ${ }^{1,2}$, Kate Gwyther ${ }^{1,2}$ and Simon M. Rice ${ }^{1,2^{*}}$
}

\begin{abstract}
The current 'state of play' in supporting elite athlete mental health and wellbeing has centred mostly on building mental health literacy or awareness of the signs of mental ill-health amongst athletes. Such awareness is necessary, but not sufficient to address the varied mental health needs of elite athletes. We call for a new model of intervention and outline the backbone of a comprehensive mental health framework to promote athlete mental health and wellbeing, and respond to the needs of athletes who are at-risk of developing, or already experiencing mental health symptoms or disorders. Early detection of, and intervention for, mental health symptoms is essential in the elite sporting context. Such approaches help build cultures that acknowledge that an athlete's mental health needs are as important as their physical health needs, and that both are likely to contribute to optimising the athlete's overall wellbeing in conjunction with performance excellence. The proposed framework aims at (i) helping athletes develop a range of self-management skills that they can utilise to manage psychological distress, (ii) equipping key stakeholders in the elite sporting environment (such as coaches, sports medicine and high-performance support staff) to better recognise and respond to concerns regarding an athlete's mental health and (iii) highlighting the need for specialist multi-disciplinary teams or skilled mental health professionals to manage athletes with severe or complex mental disorders. Combined, these components ensure that elite athletes receive the intervention and support that they need at the right time, in the right place, with the right person.
\end{abstract}

\section{Key Points}

- Currently, there is no comprehensive framework or model of care to support and respond to the mental health needs of elite athletes.

- We propose a framework that recognises the impact of general and athlete-specific risk factors, and engages key individuals that may identify and promote athlete mental health.

- The framework is adaptable and responsive to varied career stages and mental health states.

There has been a rapid increase in research examining the mental health of elite athletes culminating with the

\footnotetext{
* Correspondence: simon.rice@unimelb.edu.au

'Orygen, The National Centre of Excellence in Youth Mental Health, 35

Poplar Road, Parkville, Melbourne, Victoria 3052, Australia

${ }^{2}$ Centre for Youth Mental Health, University of Melbourne, Melbourne,

Victoria, Australia
}

International Olympic Committee's (IOC's) recent Expert Consensus Statement on mental health in elite athletes [1]. This statement provides a comprehensive analysis of, and recommendations for, the treatment of both high prevalence (e.g. anxiety and mood symptoms) and more complex mental health disorders (e.g. eating and bipolar disorders) in the elite sporting context. This is a timely resource which will help guide and ultimately improve the clinical management of athletes by sports medicine, mental health, and allied health professionals. The primary focus of the consensus statement, along with much of the extant literature, is on managing the individual athlete affected by mental illhealth. There has been little scholarly and service-level attention to more comprehensive frameworks that (a) recognise the role of the broader elite sports ecology as both a contributor to athlete mental health difficulties and a facilitator of their remediation, and (b) approaches that emphasise the prevention of mental health symptoms, along with early detection and intervention to restore athlete wellbeing (and ideally optimise performance). 


\section{Risk Factors for Mental III-health in Elite Athletes}

Meta-analytic reviews indicate that elite athletes experience broadly comparable rates of mental ill-health relative to the general population in relation to anxiety, depression, post-traumatic stress and sleep disorders [2, 3]. This should not be unexpected given the considerable overlap in the years of active elite competition and the primary ages of onset for most mental disorders [4-6].

Increasing evidence points to a range of both athletespecific and general risk factors associated with mental ill-health in elite athletes. Athlete-specific risk indicators include sports-related injury and concussion [3, 7-9], performance failure [10], overtraining (and overtraining syndrome) [11] and sport type (e.g. individual sports conferring a higher risk that team sports) [12]. General risk indicators include major negative life events [13, $14]$, low social support $[15,16]$ and impaired sleep [17, 18]. These risk factors may impact the severity and onset of particular mental health symptoms, but can also guide appropriate response strategies.

The salience of particular risk factors may vary across career phases. For example, in junior development years, supportive relationships with parents and coaches are imperative to athlete wellbeing $[19,20]$. During the high performance and elite phase, in addition to the coaching relationship, environmental and training demands become more relevant to mental health and wellbeing [21], including extended travel away from home and exposure to unfamiliar (training) environments [22]. Environmental conditions and travel may be especially salient for the mental health of para-athletes, who often encounter disruptive logistical issues associated with travel, such as a lack of adaptive sport facilities and sleeping conditions [23]. Prominent risk factors during the transition out of sport include involuntary or unplanned retirement and lack of a nonathletic identity, both of which are associated with a range of psychological challenges [24]. For para-athletes, involuntary retirement due to declassification (i.e. no longer meeting the required criteria to be classified as a para-athlete) is a unique burden [25].

\section{Optimising the Mental Health and Wellbeing of Elite Athletes: Barriers and Facilitators}

A comprehensive framework for mental health in elite athletes needs to consider the range of relevant risk factors across key career phases, as well as factors that inhibit or facilitate the ability to effectively respond to athletes' needs. Key barriers include more negative attitudes towards help-seeking amongst athletes than the general population [26], as well as greater stigma and poorer mental health literacy. Fear of the consequences of seeking help (e.g. loss of selection) and lack of time are also influential [26-28]. Facilitative factors include support and acknowledgment from coaches [27] who can help to create a non-stigmatised environment where help-seeking can be normalised [28]. Approaches that seek to optimise athletic performance while simultaneously providing intervention for mental health symptoms may also facilitate engagement [29, 30]. Brief antistigma interventions and mental health literacy programs that seek to increase knowledge of mental health symptoms have been shown to improve help-seeking intentions in elite athletes [31-33], although the impact of such programs on help-seeking behaviours is not known.

\section{Are there Existing Frameworks or Models of Care for Mental Health in Elite Sport?}

To date there are no published frameworks regarding how best to support the mental health needs of elite athletes. In addition to the IOC Consensus Statement, recent position statements have emphasised the need to build awareness of mental health problems and increase help-seeking behaviours [34-36]. These initiatives are unquestionably warranted; however, improving awareness and help-seeking behaviours are at best pointless, and at worst unsafe, if systems of care to respond to athlete's need are not available. A whole of system approach needs to be developed simultaneously.

Beyond the peer-reviewed literature, useful guidelines exist within selected sporting associations regarding supporting athlete wellbeing [37-39]. These resources highlight a number of critical factors in managing athlete mental health in the sporting context including (i) the sports' responsibility for managing the athlete's care and support (e.g. duty of care issues); (ii) the need for regular screening or monitoring of athletes to detect changes in mental state or behaviour; (iii) privacy and confidentiality regarding mental health as key ethical issues and challenges; (iv) athlete preferences for help-seeking (how and from whom); (v) the need to refer out to or engage external mental health professionals where expertise does not exist within the sporting environment; and (vi) the value of trained peer workers (former athletes/players) to provide support and guidance to athletes and to coordinate activities related to professional development needs (such as public speaking or financial planning) and individual goal-setting (e.g. around educational or post-sport vocational interests). However, no single framework incorporates all of these factors nor is there a framework that focuses on the spectrum of athlete/player mental health needs, from symptom prevention to specialist mental health care. There has been some progress in developing mental health guidelines in collegiate-level athletes [4042], which highlight the need to provide specific and targeted support, while noting that few comprehensive or targeted models of care for mental health have been developed for this population. 


\section{Developing a Comprehensive Mental Health Framework to Support Elite Athletes}

Many of the general and athlete-specific risk factors for mental ill-health are potentially modifiable (e.g. coping strategies, coaching style, training demands) and require intervention at the individual athlete, the sporting or environmental and/or organisational levels. A comprehensive framework for athlete mental health that is conceptualised within the broader 'ecology' of elite sporting environments will be best able to respond to the range of risk indicators in this context (see Fig. 1). Ecological systems help to explain the relationship between the aspects or experiences of an individual (termed 'ontogenetic' factors, such as coping or substance use) and the broader social and cultural contexts in which they exist [43]. In the case of elite athletes, this includes the 'microsystem' of coach(es), teammates (where appropriate) and family/loved ones. The wider sporting environment (e.g. the athlete's sport, its rules and governing body) forms the exosystem, while the role of national and international sporting bodies and the media and broader society form the macrosystem.

Any mental health framework that ignores wider ecological factors runs the risk of focusing exclusively on, and potentially pathologising the individual athlete, when other factors may be more influential in contributing to, or perpetuating poor mental health. Such factors may include maladaptive relationships with coaches or parents, social media abuse and/or financial pressures.

In addition to ecological factors, a comprehensive framework for mental health should encompass both prevention and early intervention, consistent with established models that are influential in public health and social policy (e.g. Haggerty and Mrazek's mental health promotion spectrum [44]; see Fig. 2). An early intervention framework can optimise athlete mental wellbeing and respond rapidly to mental health symptoms and disorders as they emerge to best maintain the athlete's overall function.

Within this framework, the prevention stages aim to reduce the risk of mental health symptoms developing or to minimise their potential impact and severity; the treatment and early intervention stages seek to identify and halt the progression of emerging mental health difficulties; and the continuing care stages help an individual to recover and prevent relapse, typically through ongoing clinical care with a mental health professional [44].

Based on the extant literature regarding risk factors for mental ill-health in elite athletes, along with existing sporting guidelines or statements regarding athlete wellbeing, and our experience developing and implementing early intervention services and system reform for young people's mental health [45-47], we propose the following framework to respond to the mental health of elite athletes (see Fig. 3).

\section{Preventative or 'Foundational' Components}

Core foundational components should include (i) mental health literacy to improve understanding, reduce stigma and promote early help-seeking; (ii) a focus on athlete development (both career and personal development goals) and skill acquisition to help attain these goals; and (iii) mental health screening of, and feedback to, athletes. The purpose of these foundational components is to enhance awareness of the importance of athlete wellbeing across the elite sport 'ecology'. This in turn addresses workplace duty of care and occupational health and safety responsibilities towards athletes' overall wellbeing in the context of sport-related stressors.

\section{Mental Health Literacy}

Mental health literacy programs should be provided to athletes, coaches and high-performance support staff to

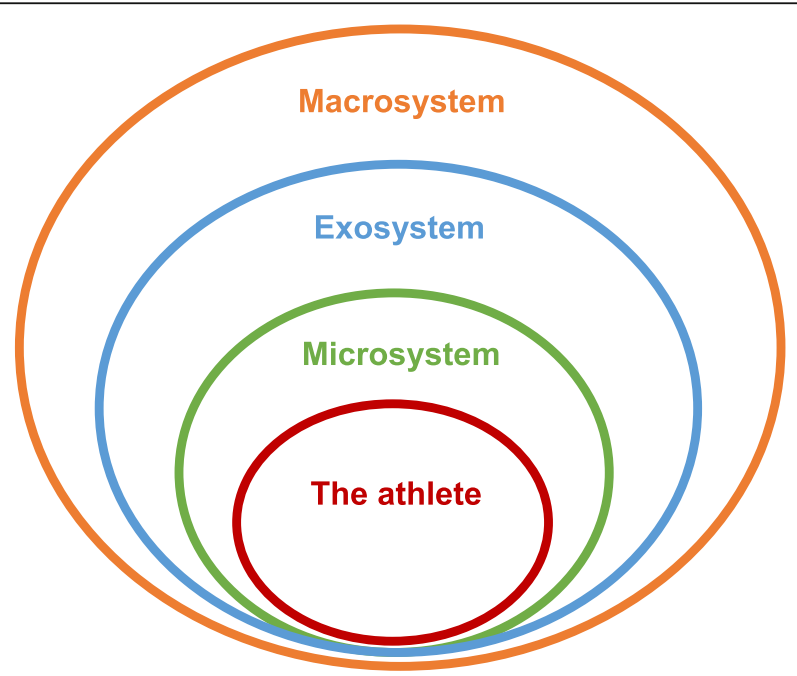

\section{Macrosystem \\ (Inter)National sporting \\ environment, public \\ and social media \\ Exosystem \\ Individual sport}

Microsystem

Coaches, parents/relatives, friends, high performance and sports medicine staff

The athlete

Coping skills, attitudes

Fig 1. An ecological systems model for elite athlete mental health 


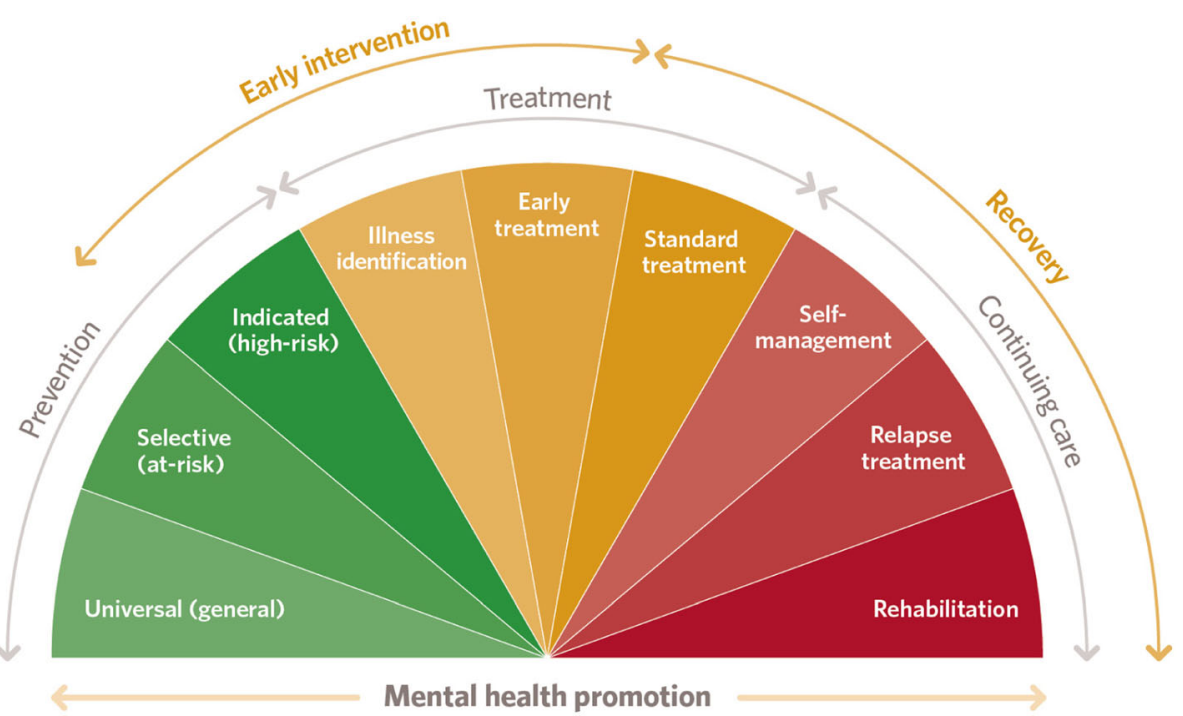

Fig 2. The mental health promotion spectrum

help to create a culture that values enhancing the mental health and wellbeing of all stakeholders. Programs should also be offered to the athlete's family or friends to build their capacity to identify symptoms and encourage help-seeking, particularly as these are the individuals from whom athletes will initially seek help and support [48, 49]. Engaging an array of individuals, including organisational staff, in these programs broadens the reach of mental health literacy within an athlete's (or sport's) ecology (see Fig. 1). Gulliver and colleagues effectively trialled the delivery of a mental health literacy program to elite athletes via team-based workshops facilitated by mental health professionals [26]. This delivery method is preferred given the opportunity for qualified facilitators to discuss and explore athlete questions or concerns (especially regarding confidentiality and the implications of help-seeking for selection) and to potentially problem-solve together. The content of such training should be customised to address the specific aspects of the sport (e.g. team-based versus individual sport) and developmental stages (e.g. junior versus retiring

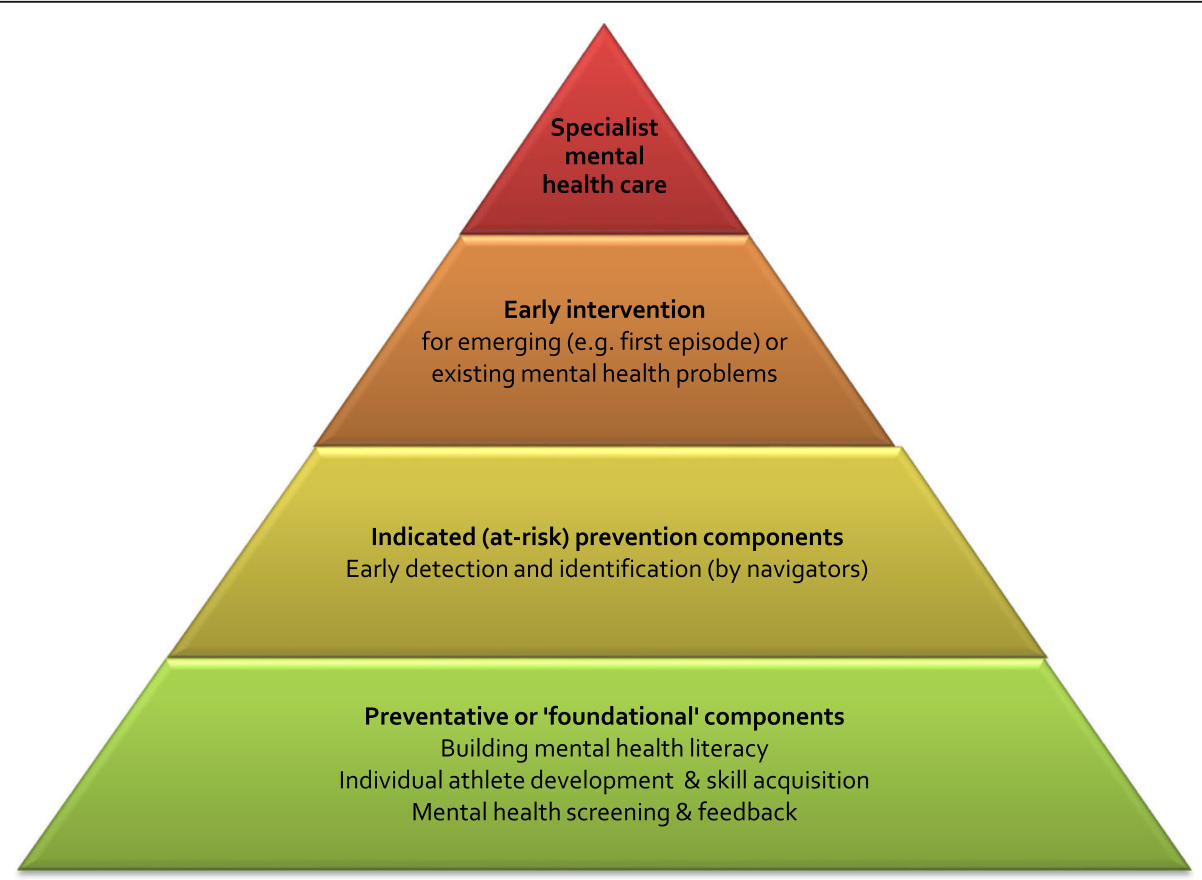

Fig 3. Elite athlete mental health and wellbeing framework 
athletes). Basic program content should cover (i) athletespecific and general risk factors that can increase susceptibility to mental ill-health; (ii) key signs or symptoms of impaired wellbeing; (iii) how and from whom to seek help, both within and outside the sport; and (iv) basic techniques for athletes to self-manage transient mood states or psychological distress, such as relaxation techniques, adaptive coping strategies, self-compassion and mindfulness.

\section{Individually Focused Development Programs}

Individually focused development programs can assist athletes to identify personal/vocational goals and acquire the skills necessary to achieve them. This is necessary to help develop a parallel non-athletic identity, the skills to manage life-sport balance and to prepare for the eventual end of competitive sport. The latter may be challenging in younger athletes who often lack the longer-term perspective or life experience to perceive the need for such planning. However, a focus on developing a nonathletic identity must occur at all phases of the sporting career and not be confined to the transition out of sport phase, since building such skills takes time (and athletes are prone to unplanned retirement due to injury). These activities are ideally facilitated by a skilled, well-trained 'peer workforce'. These are individuals who have a lived experience of mental ill-health and sufficient training to share their knowledge to help support others in similar situations [50]. In the sporting context, a peer workforce could include former athletes or coaches who work with current athletes to discuss and normalise experiences of mental health symptoms or their risk factors. Former athletes can assist with athlete development programs and mobilise athletes to the importance of actively participating with such programs, based on their own experiences [39].

\section{Mental Health Screening}

Mental health screening should be included alongside routine physical health checks by medical staff as part of a comprehensive framework. Screening items should be sensitive to the elite context $[50,51]$ and should be designed to provide feedback to athletes to help promote improved self-awareness, such as their mental state and triggers for symptoms. Critical times to screen are following severe injury (including concussion) and during the transition into, and out of sport [1], and the lead-up to and post major competitions may also be periods of higher risk. It is important to note that there is currently a lack of widely validated athlete-specific screening tools, though one elite athlete sensitised screening measurethe Athlete Psychological Strain Questionnaire-has been validated in a large sample of male elite athletes reporting strong psychometric properties [52], and is under further validation with female and junior athletes.
Research potential exists to not only develop further athlete-specific measures, but to determine who is best suited to conduct screening, and what credentials or training may be required to ensure safety and integrity in this process (e.g. that appropriate help or referral is provided to athletes who screen positive).

\section{Indicated ('at-risk') Prevention Programs}

The second phase is indicated prevention programs for those considered or assessed as being 'at-risk' of impaired mental health and wellbeing. This phase aims to mitigate the likelihood of deterioration in mental health by detecting symptoms as early as possible and facilitating referral to appropriate health professionals. Key staff within the sports system can be assisted to develop skills in early symptom identification and to promote professional help-seeking. This includes coaches, athletic trainers and teammates (where appropriate) who are in a position to notice 'micro' changes in an athlete over days or weeks, and sports medicine staff, such as physiotherapists who may detect other non-observable signs, such as changes in energy or body tension. We term these individuals 'navigators' in the mental health framework, as they have a crucial role in observing the athlete's behaviour or mental state and being able to link them to professional care. These navigators can be provided with additional training (adjunctive to mental health literacy) to better recognise and interpret the athlete's behaviour in relation to their overall wellbeing, understand athlete privacy concerns that inhibit the disclosure of mental health symptoms and build selfefficacy to be able to raise their concerns safely with the affected athlete or medical/mental health staff.

Sport administrators should also consider developing guides on 'what to do if concerned about an athlete's mental wellbeing' and make these available to all relevant staff. These should include information regarding appropriate referral sources, responses (e.g. prevention program vs. early intervention) and facilitators to engage athletes, such as support and encouragement [27, 28] and/or linking mental wellbeing with athletic performance $[29,30]$. Protocols or guides for responding to mental health concerns become less stigmatised when wellbeing needs are already routinely promoted via foundational programs.

\section{Early Intervention}

Early intervention is necessary in instances where the performance and life demands placed on an athlete exceed their ability to cope (i.e. major career-threatening injury or significant life stress). Structured clinical interventions for mild to moderate mental ill-health are typically indicated at this phase and should ideally be provided 'in-house' by mental health clinicians, such as sports or clinical psychologists or psychiatrists, or medical staff where appropriate 
(e.g. pharmacotherapy). The use of in-house professionals helps to counter the low levels of service use associated with referring athletes out to external service providers and the stigma that is associated with the athlete needing expert 'outside help' [53]. Where requisite in-house expertise does not exist, this can be managed by the use of qualified consultants, but ideally these professionals should be 'embedded' to some extent within the sporting environment to ensure that athletes and other staff understand 'who they are and what their role is', even if their presence is infrequent [54]. When referral out is necessary, or preferred by the athlete, ideally this should be to a mental health professional with appropriate sport sensitised training, knowledge and experience assisting elite athletes.

Early interventions need not always be face-to-face, but can be augmented by telephone or web-enabled consultations, the latter particularly relevant given the frequency with which elite athletes travel unaccompanied by the sporting entourage. All interventions, regardless of the mode of delivery, should use an individualised care approach that is based on assessment and conceptualisation of the individual athlete's presenting problem(s). The intervention should target the psychological processes of the athlete that are impeding mental health [55] and take account of the specific familial, sporting and organisational issues that may be impacting on the athlete's wellbeing.

An example of an early intervention model of care is the Australian Institute of Sport (AIS) mental health referral network [56]. Athletes are assessed by an AIS mental health advisor, who can make a referral, if necessary, to a qualified mental health practitioner who has been credentialed to work within the network. This practitioner then works individually with the athlete to address their needs and ideally restore their mental health and functioning [57].

\section{Specialist Mental Health Care}

Despite best efforts to prevent or intervene early, some athletes will nonetheless experience severe or complex psychopathology requiring specialist mental health care, particularly where there is a risk of harm to self or others. In some cases, this may include hospitalisation or specialist inpatient or day programs. The IOC Expert Consensus Statement provides a summary of recommended clinical interventions for a range of mental disorders, including bipolar, psychotic, eating and depressive disorders, and suicidality [1]. Developing and implementing a mental health emergency plan may also be required, particularly in cases where an athlete presents with an acute disturbance in their mental state, for instance agitation/paranoia, or suicidal ideation [58]. The IOC Expert Consensus Statement recommends that structured plans should acknowledge and define what constitutes a mental health emergency, identify which personnel (or local emergency services) are contacted and when, and consider relevant mental health legislation [1].

There is also arguably a need for 'return to sport or training' guidance for athletes who have been unable to compete or train for their sport due to mental illness, akin to guidelines for managing concussion [59]. Such guidance could potentially provide a graduated, step-by-step protocol that prepares not only the athlete for a successful return to sport, but also the microsystem that supports them.

\section{Conclusions}

We have proposed a comprehensive framework for elite athlete mental health. More research is needed to bolster the efficacy of the approaches discussed here in the elite sports context, as well as other factors that are underresearched in the literature, such as gender-specific considerations in mental health [60] and considerations for para-athletes [23]. We are mindful that coaches and other high-performance staff are vulnerable to mental health problems [61] and the needs of these individuals need to be incorporated into a more inclusive model of care. Further, we recognise the scope of this framework does not cover the needs of non-elite athletes. Elements of this framework may be tailored in the future to be applicable and contextualised for non-elite environments where there may be limited resources, less professional staffing and greater limitations in athlete schedules.

Despite the exponential increase in research interest related to athlete mental wellbeing, major service delivery and treatment gaps remain. Evaluating the efficacy of mental health prevention and intervention programs via controlled trials or other high-quality designs is urgently needed. Program evaluation should ideally adopt an ecological systems approach to account for competitionrelated, individual-vulnerability and organisational factors on mental health outcomes, for example by seeking to measure system-level variables (e.g. the degree of perceived psychological safety within the sporting organisation $[62,63])$ and individual athlete-level variables (e.g. coping skills, relationship with coach, injury history). As initiatives are evaluated and enhanced or adapted, developers should consult with elite sport organisations and individuals to ensure the relevance and sport sensitivity of their programs. Increased resources and research funding to support the evaluation and implementation of athlete mental health programs is needed, such as currently exists for managing athletes' physical health (e.g. musculoskeletal injuries, concussion).

Finally, we are acutely aware that a framework such as that articulated here requires substantial investment and that such funding is scant even in high income settings. The foundational and at-risk components lend themselves, we believe, to be adaptable to low resource settings, 
given the emphasis on athlete self-management and a trained peer workforce. Adaptations to providing early intervention in low resource settings will be needed, and innovations in general mental health can act as a blueprint [64]. Regardless of settings or resources, investment in a comprehensive response to athlete mental health needs attention if it is to ever gain parity with physical health.

\section{Abbreviations}

IOC: International Olympic Committee; AIS: Australian Institute of Sport

\section{Acknowledgements}

Not applicable.

\section{Authors' Contributions}

RP and SMR made substantial contributions to the conception of the manuscript. RP, KG and SMR drafted, revised and approved the final version.

\section{Funding}

Simon M Rice was supported by a Career Development Fellowship (APP115888) from the National Health and Medical Research Council.

\section{Availability of Data and Materials}

Not applicable.

\section{Ethics Approval and Consent to Participate}

Not applicable.

\section{Consent for Publication}

Not applicable.

\section{Competing Interests}

The authors, Rosemary Purcell, Kate Gwyther, and Simon M. Rice, declare that they have no competing interests relevant to the content of this article.

Received: 7 July 2019 Accepted: 9 October 2019

Published online: 28 November 2019

\section{References}

1. Reardon CL, Hainline B, Aron CM, Baron D, Baum AL, Bindra A, et al. Mental health in elite athletes: International Olympic Committee consensus statement (2019). British Journal of Sports Medicine. 2019;53(11):667-99. https://doi.org/10.1136/bjsports-2019-100715.

2. Gouttebarge V, Castaldelli-Maia JM, Gorczynski P, Hainline B, Hitchcock ME, Kerkhoffs GM, et al. Occurrence of mental health symptoms and disorders in current and former elite athletes: a systematic review and meta-analysis. British Journal of Sports Medicine. 2019:53(11):700-6.

3. Rice SM, Gwyther K, Santesteban-Echarri O, Baron D, Gorczynski P, Gouttebarge V, et al. Determinants of anxiety in elite athletes: a systematic review and meta-analysis. British Journal of Sports Medicine. 2019;53(11): 722-30.

4. Rice SM, Purcell R, De Silva S, Mawren D, McGorry PD, Parker AG. The mental health of elite athletes: a narrative systematic review. Sports Med. 2016:46(9):1333-53. https://doi.org/10.1007/s40279-016-0492-2

5. Allen SV, Hopkins WG. Age of peak competitive performance of elite athletes: a systematic review. Sports Medicine. 2015:45(10):1431-41.

6. Kessler RC, Berglund P, Demler O, Jin R, Merikangas KR, Walters EE. Lifetime prevalence and age-of-onset distributions of DSM-IV disorders in the National Comorbidity Survey Replication. Archives of general psychiatry. 2005:62(6):593-602.

7. Gulliver A, Griffiths KM, Mackinnon A, Batterham PJ, Stanimirovic R. The mental health of Australian elite athletes. Journal of science and medicine in sport. 2015;18(3):255-61.

8. Peluso MAM, Andrade LHSGd. Physical activity and mental health: the association between exercise and mood. Clinics. 2005:60(1):61-70.

9. Rice SM, Parker AG, Rosenbaum S, Bailey A, Mawren D, Purcell R. Sportrelated concussion and mental health outcomes in elite athletes: a systematic review. Sports medicine. 2018;48(2):447-65.
10. Hammond T, Gialloreto C, Kubas H, Davis HH IV. The prevalence of failurebased depression among elite athletes. Clinical Journal of Sport Medicine. 2013;23(4):273-7.

11. Frank R, Nixdorf I, Beckmann J. Depression among elite athletes: prevalence and psychological factors. Deut Z Sportmed. 2013;64:320-6.

12. Schaal K, Tafflet M, Nassif $H$, Thibault V, Pichard C, Alcotte M, et al. Psychological balance in high level athletes: gender-based differences and sport-specific patterns. PLoS One. 2011;6(5):e19007. https://doi.org/10.1371/ journal.pone.0019007.

13. Nixdorf I, Frank R, Hautzinger M, Beckmann J. Prevalence of depressive symptoms and correlating variables among German elite athletes. Journal of Clinical Sport Psychology. 2013;7(4):313-26.

14. Gouttebarge V, Aoki H, Verhagen EA, Kerkhoffs GM. A 12-month prospective cohort study of symptoms of common mental disorders among European professional footballers. Clinical Journal of Sport Medicine. 2017:27(5):487-92.

15. Gutmann MC, Pollock ML, Foster C, Schmidt D. Training stress in Olympic speed skaters: a psychological perspective. The Physician and Sportsmedicine. 1984;12(12):45-57.

16. Kotnik B, Tušak M, Topič MD, Leskošek B. Some psychological traits of Slovenian Olympians (Beijing 2008) —a gender comparison. Kinesiologia Slovenica. 2012;18(2).

17. Gupta L, Morgan K, Gilchrist S. Does elite sport degrade sleep quality? A systematic review. Sports Medicine. 2017:47(7):1317-33.

18. Kölling S, Steinacker JM, Endler S, Ferrauti A, Meyer T, Kellmann M. The longer the better: sleep-wake patterns during preparation of the world rowing junior championships. Chronobiology international. 2016;33(1):73-84.

19. Berntsen H, Kristiansen E. Guidelines for Need-Supportive Coach Development: The Motivation Activation Program in Sports (MAPS) International Sport Coaching Journal. 2019;6(1):88-97.

20. Sabato TM, Walch TJ, Caine DJ. The elite young athlete: strategies to ensure physical and emotional health. Open access journal of sports medicine. 2016;7:99

21. Saw AE, Main LC, Gastin PB. Monitoring the athlete training response: subjective self-reported measures trump commonly used objective measures: a systematic review. British Journal of Sports Medicine. 2016;50(5): 281-91. https://doi.org/10.1136/bjsports-2015-094758.

22. Donnelly AA, Macintyre TE, O'Sullivan N, Warrington G, Harrison AJ, Igou ER, et al. Environmental influences on elite sport athletes well being: from gold, silver, and bronze to blue green and gold. Frontiers in psychology. 2016;7:1167.

23. Swartz L, Hunt X, Bantjes J, Hainline B, Reardon CL. Mental health symptoms and disorders in Paralympic athletes: a narrative review. British Journal of Sports Medicine. 2019:bjsports-2019-100731.

24. Knights S, Sherry E, Ruddock-Hudson M. Investigating elite end-of-athleticcareer transition: a systematic review. Journal of Applied Sport Psychology. 2016:28(3):291-308

25. Bundon A, Ashfield A, Smith B, Goosey-Tolfrey VL. Struggling to stay and struggling to leave: The experiences of elite para-athletes at the end of their sport careers. Psychology of Sport and Exercise. 2018;37:296-305.

26. Gulliver A, Griffiths KM, Christensen H. Barriers and facilitators to mental health help-seeking for young elite athletes: a qualitative study. BMC psychiatry. 2012;12(1):157.

27. Castaldelli-Maia JM. Gallinaro JGdMe, Falcão RS, Gouttebarge V, Hitchcock ME, Hainline B et al. Mental health symptoms and disorders in elite athletes: a systematic review on cultural influencers and barriers to athletes seeking treatment. British Journal of Sports Medicine. 2019;53(11):707-21. https://doi. org/10.1136/bjsports-2019-100710.

28. Reardon CL, Factor RM. Sport psychiatry: A systematic review of diagnosis and medical treatment of mental illness in athletes. Sports Medicine. 2010;40(11):961-80.

29. Donohue B, Gavrilova Y, Galante M, Gavrilova E, Loughran T, Scott J, et al. Controlled evaluation of an optimization approach to mental health and sport performance. Journal of Clinical Sport Psychology. 2018;12(2):234-67.

30. Gavrilova Y, Donohue B, Galante M. Mental health and sport performance programming in athletes who present without pathology: A case examination supporting optimization. Clinical Case Studies. 2017;16(3):23453

31. Bapat S, Jorm A, Lawrence K. Evaluation of a mental health literacy training program for junior sporting clubs. Australasian psychiatry. 2009;17(6):475-9.

32. Beauchemin J. College student-athlete wellness: An integrative outreach model. College Student Journal. 2014;48(2):268-80.

33. Kern A, Heininger W, Klueh E, Salazar S, Hansen B, Meyer T, et al. Athletes connected: results from a pilot project to address knowledge and attitudes 
about mental health among college student-athletes. Journal of Clinical Sport Psychology. 2017;11(4):324-36.

34. Henriksen K, Schinke R, Moesch K, McCann S, Parham William D, Larsen CH, et al. Consensus statement on improving the mental health of high performance athletes. International Journal of Sport and Exercise Psychology. 2019:1-8. https://doi.org/10.1080/1612197X.2019.1570473.

35. Moesch K, Kenttä G, Kleinert J, Quignon-Fleuret C, Cecil S, Bertollo M. FEPSAC position statement: mental health disorders in elite athletes and models of service provision. Psychology of Sport and Exercise. 2018.

36. Schinke RJ, Stambulova NB, Si G, Moore Z. International society of sport psychology position stand: Athletes' mental health, performance, and development. International journal of sport and exercise psychology. 2018; 16(6):622-39.

37. Queensland Academy of Sport. Athlete wellbeing framework. Queensland Academy of Sport, https://www.qasport.qld.gov.au/about/documents/qasathlete-wellbeing-framework.pdf. 2014. Accessed 20 May 2019.

38. Lomax L. System recognises importance of support to help athletes with mental health issues. English Institute of Sport, https://www.eis2win.co.uk/2 014/08/21/system-recognises-importance-support-help-athletes-mentalhealth-issues/. 2014.

39. Australian Football League Players' Association. Development and wellbeing report 2014. Australian football league players' association, http://www. aflplayers.com.au/wp-content/uploads/2015/03/Dev-Wellbeing-2015.pdf. 2014. Accessed 20 May 2019

40. Brown GT, Hainline B, Kroshus E, Wilfert M. Mind, body and sport: understanding and supporting student-athlete mental wellness. IN: NCAA: Indianapolis; 2014.

41. Neal TL, Diamond AB, Goldman S, Klossner D, Morse ED, Pajak DE, et al. Inter-association recommendations for developing a plan to recognize and refer student-athletes with psychological concerns at the collegiate level: an executive summary of a consensus statement. Journal of Athletic Training. 2013;48(5):716-20.

42. Thompson R, Sherman R. Managing student-athletes' mental health issues. National Collegiate Athletic Association: Indianapolis; 2007.

43. Bronfenbrenner U. Ecological systems theory: Jessica Kingsley Publishers; 1992.

44. Haggerty RJ, Mrazek PJ. Reducing risks for mental disorders: Frontiers for preventive intervention research: National Academies Press; 1994.

45. Purcell R, Goldstone S, Moran J, Albiston D, Edwards J, Pennell K, et al. Toward a Twenty-First Century Approach to Youth Mental Health Care. International Journal of Mental Health. 2011;40(2):72-87. https://doi.org/10. 2753/IMH0020-7411400204.

46. McGorry PD, Purcell R, Goldstone S, Amminger GP. Age of onset and timing of treatment for mental and substance use disorders: implications for preventive intervention strategies and models of care. Current opinion in psychiatry. 2011;24(4):301-6.

47. Rice SM, Purcell R, McGorry PD. Adolescent and young adult male mental health: transforming system failures into proactive models of engagement. Journal of Adolescent Health. 2018;62(3):S9-S17.

48. Pierce D, Liaw S-T, Dobell J, Anderson R. Australian rural football club leaders as mental health advocates: an investigation of the impact of the Coach the Coach project. International journal of mental health systems. 2010;4(1):10.

49. Naoi A, Watson J, Deaner H, Sato M. Multicultural issues in sport psychology and consultation. International Journal of Sport and Exercise Psychology. 2011:9(2):110-25.

50. Vandewalle J, Debyser B, Beeckman D, Vandecasteele T, Van Hecke A, Verhaeghe S. Peer workers' perceptions and experiences of barriers to implementation of peer worker roles in mental health services: A literature review. International Journal of Nursing Studies. 2016;60:234-50.

51. Donohue B, Galante M, Hussey J, Lee B, Paul N, Perry JE, et al. Empirical Development of a Screening Method to Assist Mental Health Referrals in Collegiate Athletes. Journal of Clinical Sport Psychology. 2019:1-28. https:// doi.org/10.1123/jcsp.2018-0070

52. Rice SM, Parker AG, Mawren D, Clifton P, Harcourt P, Lloyd M, et al. Preliminary psychometric validation of a brief screening tool for athlete mental health among male elite athletes: the Athlete Psychological Strain Questionnaire. International Journal of Sport and Exercise Psychology. 2019:1-16.

53. McDuff DR. Sports psychiatry: strategies for life balance and peak performance. American Psychiatric Pub; 2012.

54. Morse ED. Sports Psychiatrists Working in College Athletic Departments. Clinical Sports Psychiatry. 1988;203.
55. Moore ZE, Bonagura K. Current opinion in clinical sport psychology: from athletic performance to psychological well-being. Current opinion in psychology. 2017;16:176-9.

56. Australian Institute of Sport. Mental health referral network: Support for elite AIS-funded athletes with mental health concerns. SportAus, https://www. sportaus.gov.au/ais/MHRN. 2018. Accessed 20 May 2019.

57. Rice S, Butterworth M, Clements M, Josifovski D, Arnold S, Schwab C, et al Development and implementation of the national mental health referral network for elite athletes: A case study of the Australian Institute of Sport. Case Studies in Sport and Exercise Psychology. Under review. .

58. Currie A, McDuff D, Johnston A, Hopley P, Hitchcock ME, Reardon CL et al. Management of mental health emergencies in elite athletes: a narrative review. British Journal of Sports Medicine. 2019:bjsports-2019-100691. doi:10. 1136/bjsports-2019-100691.

59. McCrory P, Meeuwisse W, Dvorak J, Aubry M, Bailes J, Broglio S, et al. Consensus statement on concussion in sport-the 5th international conference on concussion in sport held in Berlin, October 2016. Br J Sports Med. 2017:51(11):838-47.

60. Rice SM, Fallon BJ, Aucote HM, Möller-Leimkühler AM. Development and preliminary validation of the male depression risk scale: Furthering the assessment of depression in men. Journal of affective disorders. 2013;151(3):950-8.

61. Carson F, Walsh J, Main LC, Kremer P. High performance coaches' mental health and wellbeing: Applying the areas of work life model. International Sport Coaching Journal. 2018;5(3):293-300.

62. Spink KS, Wilson KS, Brawley LR, Odnokon P. The perception of team envrionment: The relationship between the psychological climate and members' perceived effort in high-performance groups. Group Dynamics: Theory, Research, and Practice. 2013;17(3):150-61.

63. Stachan L, Côté J, Deakin J. A new view: Exploring positive youth development in elite sport contexts. Qualitative Research in Sport, Exercise and Health. 2011;3(1):9-32.

64. Chibanda D, Weiss HA, Verhey R, Simms V, Munjoma R, Rusakaniko S, et al. Effect of a primary care-based psychological intervention on symptoms of common mental disorders in Zimbabwe: a randomized clinical trial. Jama. 2016:316(24):2618-26.

\section{Publisher's Note}

Springer Nature remains neutral with regard to jurisdictional claims in published maps and institutional affiliations.

\section{Submit your manuscript to a SpringerOpen ${ }^{\circ}$ journal and benefit from:}

- Convenient online submission

- Rigorous peer review

- Open access: articles freely available online

High visibility within the field

- Retaining the copyright to your article

Submit your next manuscript at $>$ springeropen.com 